\title{
Adult-as-Schoolgirl Sexual Fantasies: Investigating Their Relationship With Sexual Interest in Children Within a Male Sample
}

\author{
Maja Henek ${ }^{a}$, Ross M. Bartels ${ }^{a}$ \\ [a] School of Psychology, University of Lincoln, Lincoln, United Kingdom.
}

Sexual Offending: Theory, Research, and Prevention, 2020, Vol. 15(1), Article e3069, https://doi.org/10.5964/sotrap.3069

Received: 2019-10-07 • Accepted: 2020-03-21 • Published (VoR): 2020-07-22

Handling Editor: L. Maaike Helmus, Simon Fraser University, Burnaby, BC, Canada

Corresponding Author: Ross M. Bartels, School of Psychology, University of Lincoln, Brayford Pool, Lincoln, LN6 7TS, UK. Tel: +44 (0)1522 886862. E-mail: rbartels@lincoln.ac.uk

\begin{abstract}
Theory and research indicates that sexual fantasies about children are associated with child sexual abuse and the proclivity to engage in child sexual abuse. The present study aimed to add to the literature by examining whether sexual fantasies depicting an adult partner dressed in school uniform are related to a self-reported sexual interest/proclivity towards child sexual abuse. We also investigated whether Adult-as-Schoolgirl sexual fantasies are related to other factors underlying the reason for finding children sexually appealing (e.g. lower self-esteem, the need for sexual dominance, and innocence-related fantasies). The measures assessing each variable were completed in randomized order by 87 community males recruited online (after data cleaning). The results showed significant correlations between Adult-as-Schoolgirl sexual fantasies and the interest in/ proclivity to sexually offend against children, as well as sexual fantasies about innocence in general. A direct multiple regression revealed that these two variables statistically predicted Adultas-Schoolgirl sexual fantasy scores. The present study provides the first indication that Adult-asSchoolgirl fantasies are linked to the self-reported interest and proclivity in sexually abusing children. Given the correlational nature of these findings, the causal direction cannot be determined. Moreover, the results do not indicate that people with Adult-as-Schoolgirl fantasies will act up these fantasies with a real child. Nevertheless, the findings suggest the need to address the sexualization of schoolgirl uniforms in popular media. Future research should aim to uncover the impact that Adult-as-Schoolgirl sexual fantasies have on actual behavior.
\end{abstract}

\section{Keywords}

sexual fantasies, schoolgirl sexual fantasies, proclivity, innocence, child sexual abuse 


\section{Highlights}

- Adult-as-Schoolgirl sexual fantasies were reported in $66.3 \%$ of the sample.

- Interest in child sexual abuse correlated with and predicted Adult-asSchoolgirl fantasies.

- Partner-as-Innocent fantasies correlated with and predicted Adult-asSchoolgirl fantasies.

- As expected, the need for sexual submission was not correlated with Adult-asSchoolgirl fantasies.

The sexualization of children is an ever-growing concern among the public, academic scholars, and policy-makers, particularly in relation to the negative effects it can have on young girls (Bragg et al., 2011; Durham, 2009; O’Donohue et al., 1997; Papadopoulos, 2010; Zurbriggen, 2018). A seminal report in 2007 on the sexualization of girls by the American Psychological Association Task Force noted that the sexualization of children is especially evident within commercial marketing (e.g., sexualized toys, provocative clothing intended for children) and popular media (e.g., movies, television, magazines). As Jewkes (2010) notes, the sexualization of children can also occur at the other extreme, wherein older teenagers (over 16 years old) and adult women are seen dressed in a manner that sexualizes female childhood. This can often be observed within the music industry. For example, Emma Bunton (aka 'Baby Spice') from the Spice Girls has been photographed in baby-like attire with a lollipop in her mouth (Jewkes, 2010). Perhaps the most common depiction of sexualized female childhood within music videos, however, has been the schoolgirl uniform, with the most well-known example being the music video for the song “... Baby One More Time” by Britney Spears. In the video, the (then) 17-year-old popstar was seen dressed in a Catholic school uniform with her hair in pigtails. Highlighting the sexualized portrayal of Britney's attire, Durham (2009) notes that her shirt was "tied high above her midriff and the skirt shortened to micro-mini brevity" (p. 113). Similarly, in their music video for the song 'All the Things She Said', the Russian pop duo t.A.T.u wore Catholic schoolgirl uniforms while kissing in the rain. An "overtly sexual schoolgirl look" was also adopted by the pop group Girls Aloud in their music video for the song 'St Trinian's Chant' (Jewkes, 2010, p. 8).

As mentioned earlier, there is a concern as to how these sexualized depictions of female children affect young girls in relation to their sense of self-esteem and their striving to live up to an unrealistic ideal (Papadopoulos, 2010). For example, Read (2011) argued that the portrayal of Britney Spears as a young school girl dancing with all her friends incites a desire in young girls to be the same; namely, "the popular girl" (p. 11). However, Read (2011) also states that this same portrayal of Britney appeals to "masculine fantasies of the sexually precocious schoolgirl" (p. 11). This highlights a further concern. That is, since it arguably blurs the boundaries between expressions 
of childhood and adult sexuality (Jewkes, 2010), what effect does portraying women as schoolgirls have upon adult men? For some, it may, indeed, appeal to an existing sexual interest or fantasy. For others, it may serve as a source for new sexual fantasy content. Unfortunately, to our knowledge, there has been no research on this topic.

However, there is some indication that men find the idea of having an adult female partner wear school uniform sexually appealing. For example, the results of the ' 2015 SKYN Condoms Millennial Sex Survey' (based on over 5,000 men and women aged 18 to 34 ) revealed that $18 \%$ of men like their female partner to dress up as a schoolgirl. In a study by Turner-Moore and Waterman (2017) involving a sample of 279 men (93 convicted for a sexual offence, 93 convicted for a non-sexual offence, and 93 community men), there was some indication of the adult-as-schoolgirl fantasy. For example, one man reported that his favorite sexual fantasy "is to have a young lady in schoolgirl uniform, but not under-aged, and to spank her while having sex from behind” (p. 122). Turner-Moore and Waterman (2017) refer to school uniform within these fantasies as being "fetishized" (p. 121), which Bhugra and De Silva (1996) acknowledge in their paper on the functions and purposes of uniforms. Indeed, a 'schoolgirl uniform fetish' has been conceptualized as being the derivation of sexual pleasure from viewing others dressed as a schoolgirl (Kaye, 2012). Although this definition does not specify who "others" refers to (e.g., children, adults, or both), it has been claimed that a school uniform fetish does not reflect a sexual attraction to young girls, but rather a sexual arousal elicited by the outfit itself (David, 2012). This perhaps bears similarity to 'burusera' (the sexual attraction to the uniform of young schoolgirls), which became commoditized in Japan during the 1990s through, for example, burusera shops that sold schoolgirl uniforms and other related clothing items (Hamm, 2012).

The question remains, then, as to why the schoolgirl uniform is sexually appealing to some men. In their discussion of uniforms, Bhugra and De Silva (1996) state that school uniforms signify identity. Thus, it could be argued that some men are attracted to the identity that the schoolgirl uniform denotes, which is childhood and arguably innocence and submissiveness (Durham, 2009). Indeed, when speaking about his book Katlick School in a magazine, the fashion photographer, Santé D'Orazio, stated that the school uniform signifies "virginity, the untouched, the ideal, the romantic notion of pure" (Durham, 2009, p. 114). Thus, schoolgirl uniforms may be incorporated into some men's sexual fantasies to heighten or accentuate the characteristic of innocence.

Wilson and Cox (1983) found that innocence was deemed the most attractive characteristic of children in community men with a pedophilic sexual interest. Similarly, men who have sexually offended against children have been found to harbor a greater sexual attraction towards submissiveness relative to men who had sexually abused an adult woman (Kanters et al., 2016). Thus, it is possible that some community men with a sexual interest in children and some men with a history of sexual offending incorporate the schoolgirl uniform into their sexual fantasy content due to its inherent relationship with 
submissiveness and innocence. There is some indirect support for this proposition. For example, a few published case studies have noted that some men who have sexually offended against children (Akerman et al., 2015) and who have used online child sexual exploitation material (Merdian et al., 2017) have engaged in schoolgirl role-plays with their adult partner.

Most notable, however, are the findings from the study by Turner-Moore and Waterman (2017). When examining sexual fantasies about children in a sample of 279 men (93 of whom had sexually offended), it was found that $44.1 \%$ of those reporting child-related fantasies described oral and penetrative sex with an unknown, attractive 13-15 year old female child or schoolgirl, with school uniform often being included within the fantasy description. For example, one participant stated that they sexually fantasized about "only school girls aged 13-16. They would have to be in school uniform short skirt, no stockings", while another stated "I like to think about lesbian school girls" (p. 120). Interestingly, more community males (53.8\%) reported using these fantasies relative to men who had sexually offended (38.1\%). This is important to note because child-related sexual fantasies were found to be associated with a greater proclivity to sexually offend against children in the community males, supporting other research showing the link between child-related sexual fantasies and the sexual abuse of children in community men (Klein et al., 2015). However, it should be noted that the qualitative examples given by Turner-Moore and Waterman (2017) refer to age ranges that suggest a peripubertal or hebephilic sexual interest (e.g., 13-15 years old). Thus, the inclusion of school uniforms into one's sexual fantasies may indicate a specific sexual interest in pubescent children.

Moreover, it is not clear from these findings whether the link between sexual fantasies and child-related sexual interests (and indeed the sexual fantasy-abuse association) pertains to fantasies involving an adult partner dressed in schoolgirl uniform. It is possible that Adult-as-Schoolgirl fantasies have no association with a sexual interest in children but rather a sexual interest in sexually mature post-adolescents, which is neither uncommon nor atypical (Seto, 2017). Indeed, youth-oriented pornography involving postpubescent females (aged 18-19) is a very common category in users of easily accessible legal online pornography (Hald \& Štulhofer, 2016; Ogas \& Gaddam, 2011; Walker et al., 2016). Such pornography often involves sexualized post-pubescent females wearing schoolgirl uniforms (Vannier et al., 2014). Thus, Adult-as-Schoolgirl fantasies may reflect an attraction towards sexualized attire worn by post-pubescent females. On the basis of these points, the present study was formulated.

\section{Present Study}

The present study aimed to test the hypothesis that, in a sample of community men, a sexual interest in (and proclivity to sexually abuse) children would be associated with sexual fantasies of one's adult partner dressed as a schoolgirl. A secondary aim 
involved investigating the relationship between adult-as-schoolgirl sexual fantasies and other theoretically relevant factors. Specifically, low self-esteem has been theorized to be an etiological factor of child sexual abuse (Marshall, 1996; Ward \& Beech, 2006). Thus, some men with lower self-esteem may attempt to achieve dominance over children given their inherent innocence (Baumgartner et al., 2002; Kanters et al., 2016; Scarlett, 1987). If schoolgirl uniforms denote innocence (as suggested within the literature), low self-esteem and the need for sexual dominance (but not sexual submission) may be associated with the use of Adult-as-Schoolgirl sexual fantasies, along with the use of general innocence-related sexual fantasies.

\section{Method}

\section{Design}

The study used a correlational, cross-sectional design. The tested variables included the frequency of Adult-as-Schoolgirl sexual fantasies, the proclivity towards sexual activity with a child, the frequency of innocence-related fantasies, the need for sexual dominance (and sexual submission), and self-esteem.

\section{Participants}

An initial sample of 101 men from the general community was recruited through social-media websites, such as Facebook, Twitter, and Reddit, as well as a university participation scheme. Seventy-five participants self-reported as opposite-gender attracted, 10 as same-gender attracted, and nine as bisexual. Five participants self-reported as having an 'other' sexual orientation, and one preferred to not say. Men who identified as having a same-gender attraction were unlikely to use Adult-as-Schoolgirl sexual fantasies. Thus, their data, along with the data from the two participants who did not indicate their sexual orientation, were removed in order to avoid unduly distorted results. This resulted in a sample of 89 participants, aged between 18 and 51 years old $(M=25.46$; $S D=7.02)$. Thirty-five participants identified as single, while 54 identified as being in a relationship.

\section{Measures}

\section{Interest in Child Molestation Scale (ICM)}

Using a vignette format, the ICM (Gannon \& O’Connor, 2011) assesses community participants' self-reported sexual interest and proclivity to engage in sexual activity with children. It is comprised of five vignettes that describe a scenario of sexual activity with a child. Following each vignette, participants report their level of sexual arousal, general enjoyment, and behavioral propensity to do the same behavior using a 7-point Likert scale (e.g., 1 = Not at all sexually aroused, 7 = Very strongly sexually aroused). While 
the vignettes do not state the age of the child, they use the term 'child' rather than 'teenager' and refer to contexts suggestive of younger children (e.g., babysitting, playing in a playground). Three of the vignettes describe low-force sexual acts and two describe high-force. Previous studies using the ICM have found that the low-force subscale is a particularly reliable and valid measure for assessing sexual interest in children in community samples (Gannon \& O’Connor, 2011; Mitchell \& Galupo, 2016). In light of this, only the low-force subscale was administered to the participants in the present study (see Table 1 for internal consistency).

\section{Wilson Sex Fantasy Questionnaire (WSFQ)}

The WSFQ (Wilson, 1978) assesses how often respondents use sexual fantasies. The scale is comprised of 40 specific sexual fantasies, each of which is scored on a 6-point scale (ranging from $0=$ Never to $5=$ Regularly). For the purpose of this study, four additional items were added to the WSFQ. Two of these items reflected an 'adult-as-schoolgirl' sexual fantasy (e.g., 'A partner dressing up as a "school-girl' and 'A partner pretending to be an innocent "school-girl') and two reflected a 'partner-as-innocent' sexual fantasy (e.g., 'A partner pretending they are a virgin or inexperienced in sex' and 'A partner acting innocent').

\section{The Rosenberg Self-Esteem Questionnaire (RSEQ)}

The RSEQ (Rosenberg, 1965) is a 10-item scale design to assess the levels of a respondent's self-esteem. Each item is rated on a 4-point Likert scale ranging from Strongly Disagree (1) to Strongly Agree (4). The scale measures both negative views of oneself (e.g., All in all, I am inclined to feel that I am a failure) and positive views (e.g., I am able to do things as well as most other people), with greater scores indicating higher self-esteem. Internal consistency is shown in Table 1.

\section{Need for Sexual Dominance and Submission Subscales}

These two subscales of the Sexual Functions Inventory (Nelson, 1978), each comprised of eight items, assess the importance of being sexually dominant with a partner (e.g., "Because, like many people, I enjoy the conquest") and sexually submissive with a partner (e.g., "Because sex allows me to feel vulnerable"). Each item is rated in terms of their importance using a 4-point scale, ranging from "Not at all important" (1) to "Very important” (4). Internal consistencies for each subscale are found in Table 1.

\section{Procedure}

Upon clicking the Qualtrics link, participants were directed to read and familiarize themselves with the briefing form, which explained the nature of the research. After consenting to take part, the participants were asked to provide demographics information (i.e., their age, relationship status, and sexual orientation). After this, they completed 
the five scales in a randomized order. Once completed, participants were debriefed and thanked for their help. This study gained ethical approval from the School of Psychology Research Ethics Committee at the researchers' university.

\section{Results}

Given the small sample, the risk of finding artifactual correlations is increased in a correlational study such as this. Therefore, prior to the analyses, all variables were checked for statistical outliers using a Mahalanobis Distance test. Two participants were found to have a Mahalanobis distance score that exceeded the critical value, $\chi^{2}(6)=22.46$, $p<.001$. Thus, these two participants were removed from the dataset. The descriptive statistics for each measure is presented in Table 1. Across all measures, total scores for each participant represent the average of all relevant items. As shown in Table 1, Cronbach's alphas indicated acceptable to very good levels of internal reliability across all scales, including the 'Adult-as-Schoolgirl' fantasy total. Across the sample, $66.3 \%$ reported having used a 'Adult-as-Schoolgirl' sexual fantasy at some point, while $83.1 \%$ reported using 'Partner-as-Innocent' sexual fantasies.

\section{Table 1}

Means, Standard Deviations, and Cronbach's Alphas

\begin{tabular}{lcccc}
\hline Measure & \multicolumn{3}{c}{ Possible } \\
range & $\boldsymbol{M}$ & $\boldsymbol{\alpha}$ & .82 \\
\hline Low-force ICM total & 1.13 & 0.37 & $1-7$ & .88 \\
Adult-as-Schoolgirl fantasies & 1.31 & 1.39 & $0-5$ & .68 \\
Partner-as-Innocent fantasies & 1.38 & 1.14 & $0-5$ & .88 \\
Self-esteem & 2.77 & 0.55 & $1-4$ & .77 \\
Need for sexual dominance & 2.22 & 0.57 & $1-4$ & .73 \\
Need for sexual submission & 2.26 & 0.54 & $1-4$ & \\
\hline Note. ICM
\end{tabular}

Note. ICM = Interest in Child Molestation Scale.

\section{Demographic Differences}

To examine whether the use of Adult-as-Schoolgirl fantasies differed between opposite gender-attracted men $(M=1.44, S D=1.44)$ and men identifying as bisexual $(M=0.78$, $S D=1.06)$, an independent-samples $t$-test was run. Results revealed no significant difference between opposite gender-attracted men and men identifying as bisexual, $t(80)=$ $1.33, p=.19, d=0.52$.

An independent-samples $t$-test was also run to test whether men in a relationship $(M=1.42 ; S D=1.40)$ reported using Adult-as-Schoolgirl fantasies more often than single 
men $(M=1.14, S D=1.38)$. No significant difference was found, $t(87)=0.91, p=.37, d=$ 0.20 .

\section{Correlations With Adult-as-Schoolgirl Sexual Fantasies}

The relationships between variables were investigated using Pearson's correlation coefficients (see Table 2). We followed Cohen's (1992) convention for interpreting the magnitude of the observed relationships (i.e., effect sizes). That is, an $r$ of .10 is considered small, an $r$ of .30 is considered moderate, and an $r$ of .50 is large (Cohen, 1992). As hypothesized, Adult-as-Schoolgirl sexual fantasies were positively correlated with the low-force ICM total $(r=.40, p<.001)$, suggesting that fantasizing about a partner dressing as a schoolgirl is related to a proneness to sexually offend against a child (with low force). Also, in line with our hypothesis, Adult-as-Schoolgirl sexual fantasies were significantly and strongly correlated with innocence-related sexual fantasies $(r=.59, p$ $<.001)$. Adult-as-Schoolgirl sexual fantasies did not significantly correlate with self-esteem $(r=.17, p=.12)$ or the need for sexual dominance $(r=.07, p=.52)$, which did not support our hypothesis. Also, in line with our hypothesis, the need for sexual submission was not correlated with Adult-as-Schoolgirl sexual fantasies $(r=.06, p=.59)$.

Table 2

Intercorrelations Between Variables

\begin{tabular}{lcccccc}
\hline Variable & $\mathbf{1}$ & $\mathbf{2}$ & $\mathbf{3}$ & $\mathbf{4}$ & $\mathbf{5}$ & $\mathbf{6}$ \\
\hline 1. Low-force ICM total & - & & & & & \\
2. Adult-as-Schoolgirl fantasies & $.40^{* * *}$ & - & & & & \\
3. Partner-as-Innocent fantasies & .16 & $.59^{* * *}$ & - & & & \\
4. Self-esteem & -.02 & .17 & .05 & - & & \\
5. Sexual dominance & .11 & .07 & $.25^{*}$ & -.06 & - & \\
6. Sexual submission & -.03 & .06 & $.34^{* *}$ & $-.26^{*}$ & $.44^{* * *}$ & - \\
\hline
\end{tabular}

Note. ICM $=$ Interest in Child Molestation Scale. ${ }^{*} p<.05 .{ }^{* *} p<.01 .{ }^{* * *} p<.001$.

\section{Multiple Regression}

A direct multiple regression was conducted to test whether low-force proclivity, innocence-related sexual fantasies, self-esteem, the need for sexual dominance, and the need for sexual submission statistically and incrementally predict Adult-as-Schoolgirl sexual fantasy scores. The regression model was found to be significant, $F(5,82)=15.52, p$ $<.001$. The adjusted $R^{2}$ indicated that $45.5 \%$ of the variance in low-force proclivity was accounted for by all entered variables. As shown in Table 3, the proclivity to sexually abuse children and the use of innocence-related fantasies were the only significant incremental predictors of Adult-as-Schoolgirl fantasy scores, with innocence-related fantasies 
showing the stronger relationship (i.e., a higher beta coefficient). Self-esteem, the need for sexual dominance, and the need for sexual submission were all non-statistically significant predictors, after controlling for the other variables in the model.

Table 3

Multiple Regression Results for Predicting the Adult-as-Schoolgirl Sexual Fantasies

\begin{tabular}{lccc}
\hline Variable & $\boldsymbol{\beta}$ & $\boldsymbol{t}$ & $\boldsymbol{p}$ \\
\hline Low-force proclivity & 0.31 & 3.38 & $<.001$ \\
Innocence-related sexual fantasies & 0.59 & 6.75 & $<.001$ \\
Self-esteem & 0.10 & 1.25 & .21 \\
Need for sexual dominance & -0.08 & 0.85 & .40 \\
Need for sexual submission & -0.07 & 0.76 & .45 \\
\hline
\end{tabular}

\section{Discussion}

Using a sample of men from the general community, this online study aimed to examine whether Adult-as-Schoolgirl sexual fantasies are associated with a sexual interest in (and proclivity in) sexually abusing children, along with other theoretically-identified factors (i.e., low self-esteem, the need for sexual dominance, and sexual fantasies involving innocence). The majority of the participants reported having sexually fantasized about an adult partner dressing up as a schoolgirl. Men self-reporting as opposite-gender attracted used these fantasies no more often than men identifying as bisexual. In addition, there was no significant difference in the frequency of Adult-as-Schoolgirl fantasies between single men and those in a relationship.

The main findings indicated that our primary hypothesis was supported. That is, Adult-as-Schoolgirl sexual fantasies correlated with a sexual interest/proclivity for the low-force sexual abuse of children. Thus, not only is the proclivity to engage in child sexual abuse associated with sexual fantasies involving children (Turner-Moore \& Waterman, 2017), so too are sexual fantasies involving adult women depicted as children in the form of schoolgirls. Adult-as-Schoolgirl sexual fantasies were also correlated with innocence-related sexual fantasies. No significant correlations were found between Adult-as-Schoolgirl fantasies and self-esteem, the need for sexual dominance, or the need for sexual submission. However, the need for sexual dominance was significantly correlated with innocence-related sexual fantasies, suggesting that the need to sexually dominate a partner is associated with an attraction to innocence (Kanters et al., 2016).

The multiple regression revealed that sexual interest/proclivity scores and innocence-related sexual fantasy scores statistically and independently predicted Adult-asSchoolgirl sexual fantasy scores. Thus, both variables appear to be important independent factors to consider in people who use sexual fantasies involving adult partners 
dressing as schoolgirls. It could be argued that a sexual attraction to innocence leads to the use of Adult-as-Schoolgirl sexual fantasies, as school uniforms represent innocence (Durham, 2009) and that a sexual interest in children influences the use of such fantasies as the school uniforms represent children. However, we cannot conclude this from our data as they are correlational in nature. It is, of course, possible that, since school uniforms are worn by actual young girls, the sexual arousal elicited by school uniforms may generalize to young girls, leading to an interest in engaging in sexual behavior with female children.

Either way, the results suggest there is a need to examine this topic in more depth. For example, it is possible that sexual fantasies involving children (rather than adults) wearing school uniform may result from the use of Adult-as-Schoolgirl fantasies. Previous research indicates that fantasies of children in school uniform is a common theme pertaining to child-specific sexual fantasies in both community men and men who have sexually offended (Turner-Moore \& Waterman, 2017). Thus, examining the link between Adult-as-Schoolgirl sexual fantasies and fantasies of children wearing schoolgirl uniform would be beneficial for unpacking the role that the former may play in potentially increasing the risk of sexual offending.

In addition, future research could examine the function underlying the use of Adultas-Schoolgirl fantasies. For some men, they may be perceived as a harmless way to 'spice up' one's sexual fantasies and sex life, especially if wearing school uniform for sexual purposes is normalized in society due to being relatively commonplace in popular media (e.g., music videos, magazines, television). Indeed, the 2015 SKYN survey (mentioned earlier) showed that 'schoolgirls' was the second most common sexual role-play character in men who would have grown up with these relatively commonplace media depictions (i.e., men aged between 18 and 34 years old). In addition, it is possible that Adult-as-Schoolgirl fantasies serve as a perceived 'safe' substitute for fantasizing about children in men with some of level of sexual interest in children. If so, perhaps such men lack additional risk factors (e.g., antisociality, problematic self-regulation) or harbor certain protective factors that keep them from acting upon their sexual interest in children. These further facilitatory factors should be examined in further research on this topic to establish whether they play a mediating role.

\section{Limitations}

One limitation of the present study pertains to the relatively limited sample of men. Future larger scale studies should be conducted to corroborate the findings in a more representative study. With a greater sample, modelling analyses could be conducted to test theoretically-informed causal pathways between variables. Although the use of community males helps gain insight into the proclivity for first time offending, which is useful for building up an understanding of the etiological role that Adult-as-Schoolgirl fantasies play, it would have been useful to have also collected data from men who have 
sexually offended against children. This would help establish whether such men have also used such fantasies.

Also, as with much research that relies on self-reported data, there is the issue of receiving socially desirable responses. Although the study was fully anonymous and conducted online, it is possible that participants did not answer completely honestly, especially when they were presented with scenarios of child sexual abuse. Also, no checks were included to ascertain whether participants were paying attention and answering properly (although a multivariate outlier test was conducted that may have reduced this issue somewhat). Social desirability measures and attention checks/questions should be included in future work on this topic. Another limitation is that sexual fantasies involving other 'role-play' characters were not included. Adding such items into the sexual fantasy measure would have helped establish whether Adult-as-Schoolgirl fantasies are used by people who particularly like role-playing, rather than being a specific sole sexual fantasy theme.

In spite of these limitations, this study is the first to examine and highlight the potential issue of fantasizing about adult women wearing school uniforms. The findings provide grounds for suggesting that measures should be taken to stop sexualizing schoolgirl uniforms within popular media and to dissuade men from using such fantasies and role-play scenarios. This proposition is strengthened when considering how such depictions within society may be affecting men's attitudes towards child sexual abuse (Helmus et al., 2013). For example, Machia and Lamb (2009) showed that viewing images of adult women dressed as "sexy young girls" (as well as adult women dressed in a sexual manner) increase myths about child sexual abuse. In addition, the literature would benefit from exploring adult women's view about the sexualization of school uniforms within popular media, as well as about the act of wearing school uniforms within sexual contexts with male partners.

\section{Conclusion}

The results of this study suggest that the sexual interest/proclivity to abuse children is associated with Adult-as-Schoolgirl sexual fantasies in community males. However, given the correlational nature of this study, no causal claims can be made at present. Also, the findings do not in any way indicate that people with Adult-as-Schoolgirl fantasies will actually act upon these fantasies with a real child. Thus, more research addressing the causal direction of the relationship is required. Nevertheless, the findings highlight the need to address the sexualization of schoolgirl uniforms in popular media. With further research building upon these results, informed decisions can be made as to how to tackle this issue, both at a societal and individual level. 
Funding: The authors have no funding to report.

Competing Interests: The authors have declared that no competing interests exist.

Acknowledgments: The authors have no support to report.

Data Availability: The open sharing of data was not part of the agreement/consent made by participants. Therefore, the data for this article cannot be made accessible.

\section{References}

Akerman, G., Craig, L. A., \& Beech, A. R. (2015). Treating child sex abusers: A person-centered approach. In D. T. Wilcox, T. Garrett, \& L. Harkins (Eds.), Sex offender treatment: A case study approach to issues and interventions (pp. 65-84). Chichester, United Kingdom: John Wiley \& Sons.

American Psychological Association, Task Force on the Sexualization of Girls. (2007). Report of the APA Task Force on the Sexualization of Girls. Washington, DC, USA: Author. Retrieved from http://www.apa.org/pi/women/programs/girls/report.aspx

Baumgartner, J. V., Scalora, M. J., \& Huss, M. T. (2002). Assessment of the Wilson Sex Fantasy Questionnaire among child molesters and nonsexual forensic offenders. Sexual Abuse, 14, 19-30. https://doi.org/10.1177/107906320201400102

Bhugra, D., \& De Silva, P. D. (1996). Uniforms-Fact, fashion, fantasy and fetish. Sexual and Marital Therapy, 11, 393-406. https://doi.org/10.1080/02674659608404453

Bragg, S., Buckingham, D., Russell, R., \& Willett, R. (2011). Too much, too soon? Children 'sexualization' and consumer culture. Sex Education, 11, 279-292. https://doi.org/10.1080/14681811.2011.590085

Cohen, J. (1992). A power primer. Psychological Bulletin, 112, 155-159. https://doi.org/10.1037/0033-2909.112.1.155

David. (2012, December 6). School uniform fetish [Blog post]. Retrieved from https://theromanticmisogynist.wordpress.com/2012/12/06/school-uniform-fetish/

Durham, M. G. (2009). The Lolita effect: The media sexualization of young girls and what we can do about it. Woodstock, NY, USA: Duckworth Overlook.

Gannon, T. A., \& O'Connor, A. (2011). The development of the Interest in Child Molestation Scale. Sexual Abuse, 23(4), 474-493. https://doi.org/10.1177/1079063211412390

Hald, G. M., \& Štulhofer, A. (2016). What types of pornography do people use and do they cluster? Assessing types and categories of pornography consumption in a large-scale online sample. Journal of Sex Research, 53, 849-859. https://doi.org/10.1080/00224499.2015.1065953 
Hamm, S. M. (2012). The fapanese school girl figure: Renegotiation of power through societal construction, masking a crisis of masculinity. Unpublished manuscript, University of Washington, Seattle, WA, USA.

Helmus, L., Hanson, R. K., Babchishin, K. M., \& Mann, R. E. (2013). Attitudes supportive of sexual offending predict recidivism: A meta-analysis. Trauma, Violence \& Abuse, 14, 34-53. https://doi.org/10.1177/1524838012462244

Jewkes, Y. (2010). Much ado about nothing? Representations and realities of the online soliciting of children. fournal of Sexual Aggression, 16, 5-18. https://doi.org/10.1080/13552600903389452

Kanters, T., Hornsveld, R. H. J., Nunes, K. L., Huijding, J., Zwets, A. J., Snowden, R. J., . . van Marle, H. J. C. (2016). Are child abusers sexually attracted to submissiveness? Assessment of sexrelated cognition with the Implicit Association Test. Sexual Abuse, 28, 448-468. https://doi.org/10.1177/1079063214544330

Kaye, B. (2012). ManReaders: A woman's guide to dysfunctional men. Terrace, Canada: CCB Publishing.

Klein, V., Schmidt, A. F., Turner, D., \& Briken, P. (2015). Are sex drive and hypersexuality associated with pedophilic interest and child sexual abuse in a male community sample? PLoS One, 10, Article e0129730. https://doi.org/10.1371/journal.pone.0129730

Machia, M., \& Lamb, S. (2009). Sexualized innocence: Effects of magazine ads portraying adult women as sexy little girls. Fournal of Media Psychology, 21, 15-24.

https://doi.org/10.1027/1864-1105.21.1.15

Marshall, W. L. (1996). Assessment, treatment, and theorizing about sex offenders: Developments during the past twenty years and future directions. Criminal fustice and Behavior, 23, 162-199. https://doi.org/10.1177/0093854896023001011

Merdian, H. L., Gresswell, D. M., \& Craig, L. (2017). Considering parental risk in parenting (child custody) evaluation cases involving child sexual exploitation material. In L. Dixon, D. Perkins, L. A. Craig, \& C. Hamilton-Giachritsis (Eds.), What works in child protection: An evidence-based approach to assessment and intervention in care proceedings (pp. 258-277). Hoboken, NJ, USA: Wiley-Blackwell.

Mitchell, R. C., \& Galupo, M. P. (2016). Interest in child molestation among a community sample of men sexually attracted to children. fournal of Sexual Aggression, 22, 224-232.

https://doi.org/10.1080/13552600.2015.1056263

Nelson, P. A. (1978). Personality, sexual functions, and sexual behavior: An experiment in methodology (Unpublished doctoral dissertation). University of Florida, Gainesville, FL, USA.

O’Donohue, W., Gold, S. R., \& McKay, J. S. (1997). Children as sexual objects: Historical and gender trends in magazines. Sexual Abuse, 9, 291-301. https://doi.org/10.1177/107906329700900403

Ogas, O., \& Gaddam, S. (2011). A billion wicked thoughts. New York, NY, USA: Dutton.

Papadopoulos, L. (2010). Sexualisation of young people: Review. London, United Kingdom: Home Office.

Read, B. (2011). Britney, Beyoncé, and me: Primary school girls' role models and constructions of the 'popular' girl. Gender and Education, 23, 1-13. https://doi.org/10.1080/09540251003674089 
Rosenberg, M. (1965). Society and the adolescent self-image. Princeton, NY, USA: Princeton University Press.

Scarlett, J. (1987). The sexual abuse of children. British fournal of Psychotherapy, 3, 323-331. https://doi.org/10.1111/j.1752-0118.1987.tb00987.x

Seto, M. C. (2017). The puzzle of male chronophilias. Archives of Sexual Behavior, 46, 3-22. https://doi.org/10.1007/s10508-016-0799-y

Turner-Moore, T., \& Waterman, M. (2017). Men presenting with sexual thoughts of children or coercion: Flights of fancy or plans for crime? fournal of Sexual Medicine, 14, 113-124. https://doi.org/10.1016/j.jsxm.2016.11.003

Vannier, S. A., Currie, A. B., \& O’Sullivan, L. F. (2014). Schoolgirls and soccer moms: A content analysis of free "teen" and "MILF" online pornography. fournal of Sex Research, 51, 253-264. https://doi.org/10.1080/00224499.2013.829795

Walker, A., Makin, D. A., \& Morczek, A. L. (2016). Finding Lolita: A comparative analysis of interest in youth-oriented pornography. Sexuality \& Culture, 20, 657-683. https://doi.org/10.1007/s12119-016-9355-0

Ward, T., \& Beech, A. (2006). An integrated theory of sexual offending. Aggression and Violent Behavior, 11, 44-63. https://doi.org/10.1016/j.avb.2005.05.002

Wilson, G. D. (1978). The secrets of sexual fantasy. London, United Kingdom: Dent.

Wilson, G. D., \& Cox, D. N. (1983). Personality of paedophile club members. Personality and Individual Differences, 4, 323-329. https://doi.org/10.1016/0191-8869(83)90154-X

Zurbriggen, E. L. (2018). The sexualization of girls. In C. B. Travis \& J. W. White (Eds.), Handbook of the psychology of women: Volume 1. History, theory, and battlegrounds (pp. 455-472).

Washington, DC, USA: American Psychological Association.

\section{IATSO}

International Association for the

Treatment of Sexual Offenders

Sexual Offending: Theory, Research, and Prevention is the official journal of the International Association for the Treatment of Sexual Offenders (IATSO).

leibniz-psychology.org

PsychOpen GOLD is a publishing service by Leibniz Institute for Psychology Information (ZPID), Germany. 